\title{
Arthropods in Coarse Woody Debris in Jarrah Forest and Rehabilitated Bauxite Mines in Western Australia
}

\author{
John M Koch ${ }^{1}$, Andrew H Grigg ${ }^{1}$, Ross K Gordon ${ }^{2}$ and Jonathan D Majer ${ }^{2}$ \\ ${ }^{1}$ Alcoa World Alumina, Australia. PO Box 172 Pinjarra, WA 6208 Australia; \\ ${ }^{2}$ Centre for Ecosystem Diversity and Dynamics in the Department of Environmental Biology, Curtin \\ University. GPO Box U1987 Perth WA 6845 Australia
}

Corresponding Author; john.koch@alcoa.com.au; phone +61-8-9530 2340; fax +61-8-9530 2571.

\begin{abstract}
Alcoa World Alumina Australia aims to re-establish a functioning forest ecosystem following bauxite mining in the jarrah forest of south-west Australia. Coarse woody debris (CWD) is returned to rehabilitated areas as potential fauna habitat, however, their value for invertebrate fauna has not been investigated. We sought to determine if CWD in rehabilitated areas supported a similar arthropod fauna to that on fallen logs in the adjacent unmined jarrah forest. Using emergence tents, sampling from logs in 5-year old and 15-year old rehabilitation, and in unmined forest, yielded 2266 specimens from 187 taxa. A total of 91 taxa were represented by only a single individual. Collembola (43\% of total) and Acarina (32\%) were the most abundant groups, followed by Diptera (11\%), Araneae (4\%) and Coleoptera (3\%). There were no significant differences in either taxa richness or overall abundance among the three forest site types. However, community composition varied significantly. Species richness from the Araneida, Coleoptera and Diptera was highest in the 5-year old rehabilitated forest while Collembola and Acarina were better represented in the unmined forest, related to changes in the environment surrounding the logs as rehabilitated forest develops and to $\log$ condition. The composition of arthropods on logs in the 15-year old rehabilitated forest was intermediate, indicating a trend of increasing similarity to the unmined forest in arthropod fauna as rehabilitated sites become older. We conclude that with time, CWD in rehabilitated areas is capable of supporting arthropod communities similar to those found in unmined forest. Further work is needed to determine if returning logs to mined areas facilitates the return of those taxa dependent on CWD.
\end{abstract}

Keywords; forest, logs, arthropods, bauxite, mining, rehabilitation, invertebrates, emergence tent. 


\section{Introduction}

Coarse woody debris (CWD) can be defined as "sound and rotting logs and stumps, and coarse roots in all stages of decay, that provide habitat for plants, animals and insects and a source of nutrients for soil structure and development. It consists of material generally greater than $7.5 \mathrm{~cm}$ in diameter (Stevens 1997)". However, most studies that have been conducted on CWD loosely define it as fallen dead wood with diameter at the smallest end being in excess of $10 \mathrm{~cm}$ (Grove \& Meggs 2003; Kruys \& Jonsson 1999; Nordén et al. 2004). This includes fallen branches, stumps, snags, whole fallen trees and pieces of fragmented wood (Woldendorp et al. 2004).

CWD greatly contributes to the structural complexity of the forest floor, providing a range of microclimates and microhabitats for colonising arthropods, and allowing a greater number and diversity of arthropods to coexist in one area (Harmon et al. 1986; Grove \& Meggs 2003; Jabin et al. 2004). The presence of CWD may have both indirect and direct effects on arthropod communities. The composition of arthropod communities on the forest floor has been shown to change in response to the influence of logs, and/or to litter build-up around them, due to changes in microsite moisture and temperature, or to inputs of woody fragments that alter the physical or chemical properties of the forest floor layers (Evans et al. 2003). As different types of CWD exist within the forest ecosystem (decomposition state, situation, microhabitats and species), CWD can also directly support a large variety of dependant arthropod fauna which otherwise would not be present within the area (Grove \& Meggs 2003), including those which are dependant on decaying wood microhabitats, and predatory arthropods that use CWD as areas of feeding and temporary residence.

Arthropod activity can influence the rate of decay of CWD, in addition to fungi and other microbes (Barclay et al. 2000). Many arthropods act as vectors for CWD decay, inoculating the logs with fungi via the creation of galleries and borer holes. Wood-feeding arthropods aid in decomposition by opening up wood cavity habitats and allowing other CWD dependant organisms access to the wood (Hanula 1993). In turn, the stage of decay influences the range of arthropods utilising the CWD. Arthropods that inhabit logs in earlier stages of decomposition, where the wood is harder and not as accessible, have been found to be habitat specialists, whereas those that are present in later stages of CWD decay tend to be more general in their habitat requirements (Hanula 1993).

Forest ecosystems typically show increasing amounts of dead woody material (including CWD) with increasing age (Nordén et al. 2004; Siitonen et al. 2000), although quantities can decline within over-mature stands. CWD is the slowest component of the natural forest structure to recover from major disturbance (Siitonen et al. 2000) and therefore is strongly influenced by management history. In Australia, quantities of CWD in forests have recently been reviewed by Woldendorp and Keenan (2005). They found that mass of CWD varied with forest age and with forest type, being lower in drier woodland communities and highest in wetter forests, but with significant effects of forest management. Grove and Meggs (2003) concluded that highly managed forests in Tasmania often have a dearth of CWD, with potential consequences for dependent biodiversity. However, past logging activities may increase CWD loads on the forest floor. In the jarrah forest of south-west Australia, Hingston et al. (1981) reported that fallen dead wood contributed $130 \mathrm{~T} \mathrm{ha}^{-1}$ in 
a logged stand, amounting to half of the biomass of living trees (262 $\left.\mathrm{T} \mathrm{ha}^{-1}\right)$. In older unlogged jarrah stands, quantities of CWD are typically lower (Whitford et al., unpublished data).

Mining for bauxite in the jarrah forest of south west Australia requires removal of all surface vegetation including CWD. Alcoa World Alumina Australia (Alcoa) undertakes restoration of all mined areas, with the published objective: 'To restore a self-sustaining jarrah forest ecosystem, planned to enhance or maintain water, timber, recreation and conservation values.' (Gardner 2001). To restore the conservation value, Alcoa considers it necessary to return the biodiversity and habitat diversity of the pre-mining forest. Returning CWD in the restored mined areas is an important component of this, since restored mined areas are likely to take decades or even centuries to naturally develop CWD. Since about 1990, Alcoa's restoration process has included the replacement of CWD (Koch 2007). Completion criteria requirements are a minimum of one CWD "habitat" (Fig. 1) placed in each two hectares of rehabilitated forest (Grant \& Koch 2007), although current internal standards are higher at one CWD habitat per hectare. These habitats are variable in composition and size, and can consist of logs, stumps, rocks and combinations of these. Sometimes they can be a single log. Larger woody material is generally used so as to reduce the probability of loss in a wildfire or controlled burn. Larger logs also have a higher probability of containing hollows used by a range of vertebrate fauna (Williams and Faunt, 1997). Originally, the objective of returning CWD to mined areas was to provide habitat for native vertebrate fauna; however, its importance for a wide range of ecosystem functions has more recently been recognised. The aim of the current study was to determine if CWD in rehabilitated areas had similar arthropod populations and taxa to CWD in unmined jarrah forest areas, and to determine the influence of the age of rehabilitated forest.

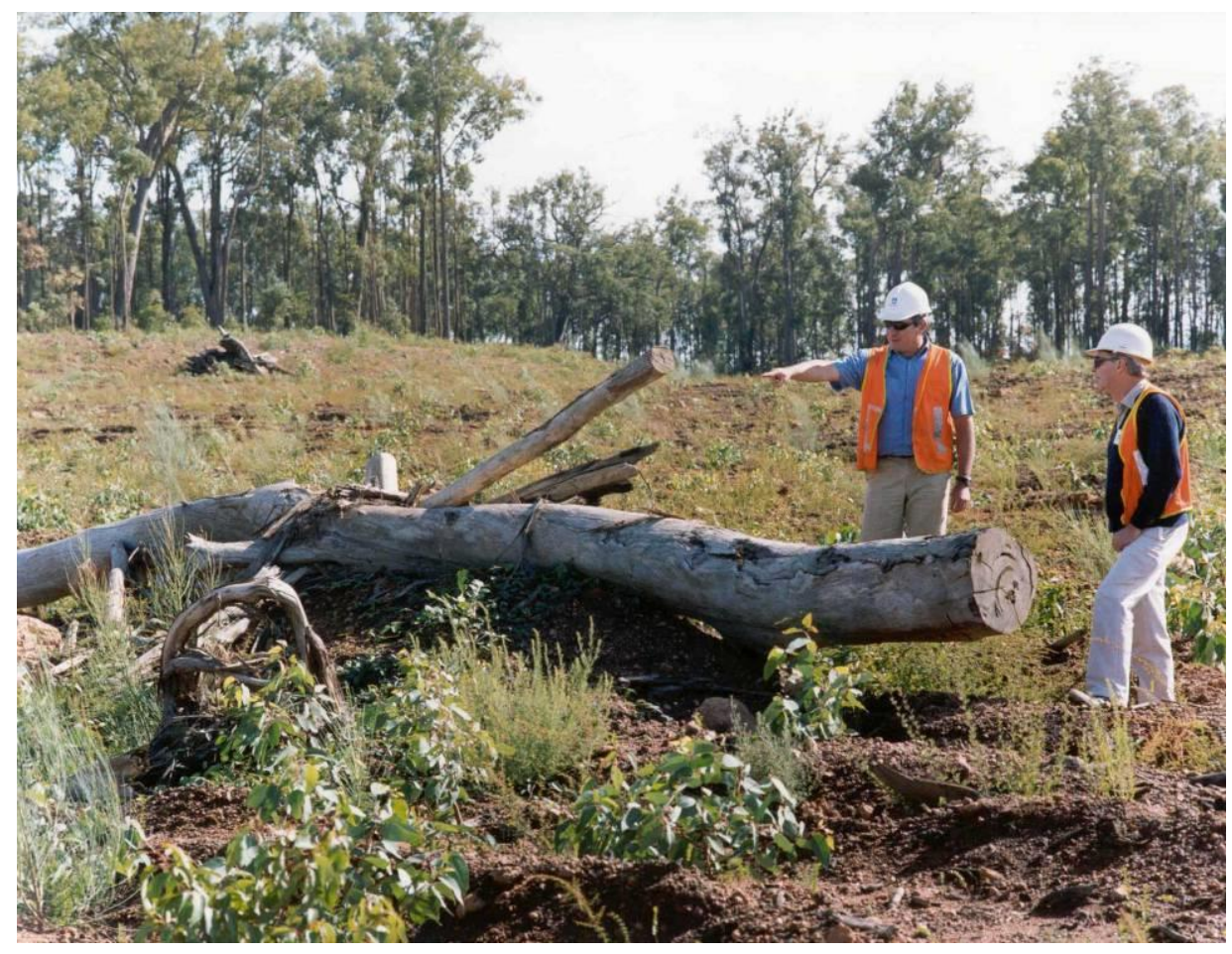

Figure 1. Example of a CWD fauna "habitat" in a rehabilitated mined area. This rehabilitated area is 1 year old. In the background is a second CWD "habitat" and unmined jarrah forest. 


\section{Methods}

Study sites and site assessment

The study was conducted at Alcoa's Jarrahdale bauxite mine, $45 \mathrm{~km}$ south-east of Perth $\left(32^{\circ} 17^{\prime} \mathrm{S}, 116^{\circ} 03^{\prime} \mathrm{E}\right)$ in the northern jarrah forest of the Darling Plateau. The climate is typically Mediterranean with mild wet winters and hot dry summers. Long-term annual rainfall averages approximately $1200 \mathrm{~mm}$. The Jarrahdale mine operated from 1963 to 1998 and the final rehabilitation was carried out in 2001. Within the mining envelope, the rehabilitated mine pits occupy about $50 \%$ of the landscape, leaving a mosaic of rehabilitated pits and unmined forest. The average pit size is about 10 hectares. For the study, a total of 24 sites were selected, eight each in 5-year old rehabilitation, 15-year old rehabilitation and unmined forest. All sites were geographically spread throughout the study region of $70 \mathrm{~km}^{2}$ with a minimum distance of $16 \mathrm{~m}$ between sites and at least $10 \mathrm{~m}$ from adjacent vegetation types and access roads to minimise edge effects. At the time of the study, the 5-year-old sites had a vigorous mid-storey of shrubs 2-3 m tall with emergent jarrah (Eucalyptus marginata) and marri (Corymbia calophylla) trees 3-5 $\mathrm{m}$ in height. In the 15-year- old sites, the mid-storey shrub layer was taller (3-4 m) but more open due to natural senescence, while the tree canopy (jarrah and marri) was mostly closed and 10-15 $\mathrm{m}$ tall. The forest sites had a more open mid-storey than both of the rehabilitated areas, with an open tree canopy of jarrah and marri 20-25 m tall.

Each site consisted of logs placed in the mined pits during the year when the rehabilitation was completed in those pits (1990 and 2000) or fallen logs in unmined forest. All logs were at least 2m in length, free of obstructions, in contact with the ground and not recently burnt. Log (mid-length) diameters ranged from 20 $\mathrm{cm}$ to $59 \mathrm{~cm}$, with equal representation of $\log$ sizes over the three forest site types. The average, maximum and minimum mid-log diameters were 42, 59, $24 \mathrm{~cm}$ (5-year-old), 40, 50, $32 \mathrm{~cm}$ (15-year-old), 34, 51, $20 \mathrm{~cm}$ (forest). Logs were mostly jarrah except for four sites which were marri.

Assessments were made of the environment immediately surrounding each log. Litter cover and cover of understorey vegetation was visually estimated within $2 \mathrm{~m}$ from the emergence tent on each $\log$. . Tree canopy cover was estimated above the same area. All logs were also assessed for their state of decay, using the Log Decay classification of Whitford and Williams (2001), and visual guides contained in Whitford et al. (2008). This 10-point classification was originally developed to estimate the age of fallen jarrah and marri logs, using attributes of bark presence, the state of sapwood and heartwood, log shape, presence and nature of fissures and cracks, the presence of moss and the nature of any branches remaining along the log. The latter was discounted in the present study for rehabilitated forest sites due to the way CWD habitats are constructed. A further attribute, the degree of contact between the log and the ground, was also not used for the same reason. Logs were given an intermediate score if they appeared to fall between two classifications. Finally, logs were given a score for the amount of surface area burnt, using a classification from Whitford et al. (2008) with scores from 0 (not burnt or only minimal burnt patches) to 5 (completely burnt). 
Sampling was carried out to assess those arthropods living in, or on, the logs. A further suite of arthropods may be associated with the soil or leaf litter beneath the logs, but sampling was not designed to assess this component of the fauna. Emergence tents were employed, using a methodology adapted from Grove and Bashford (2003). Tents were constructed in a cylindrical shape $2 \mathrm{~m}$ long using pale coloured woven shadecloth with $80 \%$ shade rating supported by flexible wire hoops (Fig. 2). The mesh had a triangular gap size of $0.8 \mathrm{~mm}$ base by $2.0 \mathrm{~mm}$ height. The mesh was sealed along the two ground edges of the $\log$ and at either end of the sampling cylinder by stapling the cloth into the wood of the log. Six collection vials were attached to each emergence tent. The vials were filled with $40-60 \mathrm{ml}$ of monoethyl-glycol. Although designed to sample log-associated fauna, the tents did collect some smaller arthropods, particularly mites and springtails, which may have moved up from the soil or litter and penetrated the mesh of the tent.

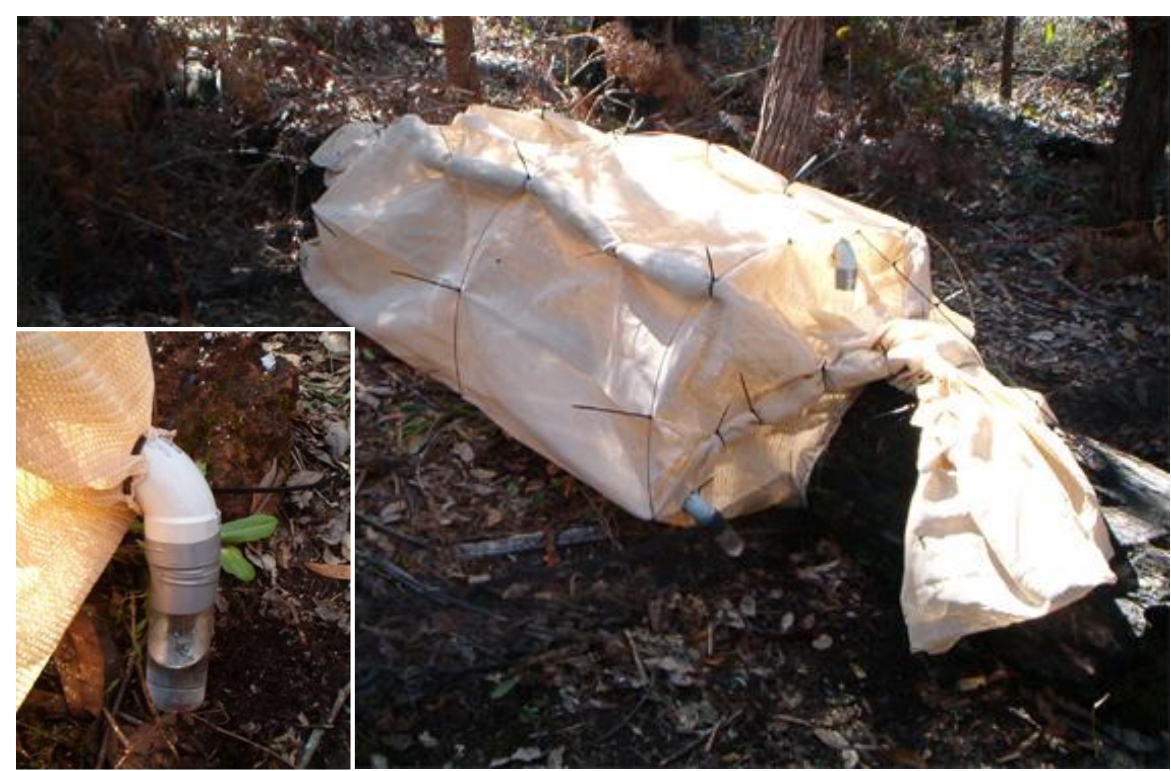

Figure 2. View of an emergence tent around a log, and detail of the collection vial system. This is a 15-yearold rehabilitated mine area.

Emergence tents were constructed in situ and sealed for sampling by mid-May 2005. They were sampled on $1^{\text {st }}$ July (45 days of enclosure), $8^{\text {th }}$ August (38 days) and $15^{\text {th }}$ September (38 days). Over the three sampling periods, there were a total of 121 days of enclosure. Specimens collected in vials were sorted to ordinal level and counted. A reference collection was made and specimens were identified by different arthropod taxonomists (listed in the acknowledgements) down to the lowest level of taxonomy possible. The terms "species" and "species richness" that are used throughout this paper include true species and morpho-species.

\section{Data analysis}

Differences in species richness and abundance among forest types were analysed by one-way ANOVA using Minitab $^{\odot}$ version 14 with a significance level of $\alpha=0.05$. We could detect no significant effect of log species (2-way ANOVA using Minitab $^{\odot}$ with forest type and log species as treatments), so sites with marri logs were 
pooled with those sampling jarrah. Abundance data exhibiting non-normal distributions were square root transformed prior to analyses. To examine differences in community composition among the two rehabilitation ages and unmined forest, we used non-metric multi-dimensional scaling (MDS) of Bray-Curtis dissimilarities using Primer $^{\odot}$ version 5.0 (Clarke and Gorley, 2006). Input data were initially transformed (log $+1)$ to reduce the influence of abundant taxa. The ANOSIM routine within Primer was used to explore differences between the a priori defined age groups and log species. We also used Canonical Analysis of Principal coordinates (CAP) of Anderson and Robinson (2003) for further ordination, again using $(\log +1)$ transformed data, and testing of differences between the age groups using canonical discriminant analysis.

We explored associations between community composition and the environmental variables collected by plotting axis scores from the MDS ordination against litter and vegetation cover estimates, and log decay score. The environmental variables best 'explaining' the community patterns were also tested using the BIOENV procedure within Primer $^{\circledR}$, after normalising the environmental variables. Tree canopy cover was closely correlated with litter cover $\left(r^{2}=0.81\right)$ and was omitted from the analysis.

\section{Results}

Taxa abundance and richness

A total of 2266 specimens from 187 taxa were collected during the study. Ninety-one taxa were represented by only one individual each, while a further 24 taxa had two individuals (Appendix 1). The majority of specimens were Collembola (springtails) (973 specimens, $43 \%$ ) or Acarina (mites) (735 specimens, $32 \%$ ), with smaller contributions from the Diptera (flies) (250 specimens, $11 \%$ ), Araneida (spiders) (82 specimens, $4 \%$ ) and Coleoptera (beetles) (72 specimens, $3 \%$ ) (Appendix 1). Over the whole study, the 5-year-old rehabilitation yielded 948 specimens, 15-year-old rehabilitation yielded 575 specimens and the jarrah forest yielded 743 specimens. The three sampling occasions yielded similar total arthropod numbers; 788, 678 and 800 specimens respectively. There was no correlation between log diameter and total abundance of arthropods captured on each log (Pearson correlation $-0.193, \mathrm{p}=0.367$ ).

There was no significant difference in mean abundance of all arthropods among the 5-year-old, 15-year-old rehabilitated and unmined forest site types (Table 1), nor any interactions between forest site type and the sampling occasion for any of the taxa. Analysis of the most abundant taxa showed that Collembola abundance was similar across all three forest site types (Table 1), but richness was significantly less in the 5-year-old rehabilitation compared to the other site types (Table 1). For Acarina, richness and abundance were significantly higher in the unmined forest compared to 15-year old rehabilitation, but not compared with 5year-old rehabilitation (Table 1). Most Araneida captured were juvenile and unable to be identified to species or morpho-species, however, richness was significantly lower in the unmined forest compared to the 5-yearold rehabilitated sites (Table 1, Appendix 1). Spider abundance showed similar trends, however, overall abundance was low and differences between forest site types were not significant. Coleopterans and Diptera typically displayed declining richness and abundance with the age of the forest type, with the 15-year-old site type indicating variable affinity with the younger 5-year old rehabilitation or the unmined forest (Table 1). 
Table 1. Mean abundance and species richness per log for various arthropod taxa for 5-year-old rehabilitation, 15-year-old rehabilitation and unmined forest (UF). Data are pooled across the three sampling periods. Numbers in brackets are standard errors. For taxa displaying significant differences (in bold), numbers with the same letter are not significantly different at $\mathrm{p}=0.05$.

\begin{tabular}{|c|c|c|c|c|c|c|c|c|}
\hline \multirow{2}{*}{ Taxon } & \multicolumn{4}{|c|}{ Abundance } & \multicolumn{4}{|c|}{ Richness } \\
\hline & 5 уо & 15 yo & UF & $\mathrm{p}$ & 5 yo & 15 yo & UF & $\mathrm{P}$ \\
\hline All arthropods & $40.4(7.1)$ & $24.0(2.7)$ & $31.1(3.2)$ & .064 & $11.1(1.2)$ & $10.2(0.6)$ & $10.3(0.8)$ & .728 \\
\hline Collembola & $18.4(6.0)$ & $9.7(1.2)$ & $12.5(1.9)$ & .263 & $2.2^{\mathrm{a}}(0.3)$ & $3.4^{b}(0.3)$ & $4.0^{b}(0.3)$ & .000 \\
\hline Acarina & $10.3^{\mathrm{ab}}(2.0)$ & $5.7^{b}(1.9)$ & $14.7^{\mathrm{a}}(2.3)$ & .011 & $2.2^{\mathrm{ab}}(0.2)$ & $2.0^{\mathrm{a}}(0.2)$ & $2.9^{b}(0.2)$ & .016 \\
\hline Araneida & $1.4(0.4)$ & $1.5(0.4)$ & $0.6(0.3)$ & .191 & $1.2^{\mathrm{ab}}(0.3)$ & $0.9^{b}(0.2)$ & $0.4^{\mathrm{a}}(0.1)$ & .037 \\
\hline Coleoptera & $2.5^{\mathrm{a}}(1.3)$ & $0.1^{b}(0.1)$ & $0.2^{\mathrm{ab}}(0.1)$ & .045 & $1.1^{\mathrm{a}}(0.3)$ & $0.2^{\mathrm{b}}(0.1)$ & $0.2^{\mathrm{b}}(0.1)$ & .001 \\
\hline Diptera & $4.2^{\mathrm{a}}(0.6)$ & $5.3^{\mathrm{a}}(0.6)$ & $1.4^{\mathrm{b}}(0.3)$ & .000 & $2.3^{\mathrm{a}}(0.3)$ & $2.3^{\mathrm{a}}(0.2)$ & $1.1^{b}(0.3)$ & .002 \\
\hline
\end{tabular}

Significantly higher numbers of arthropod species were trapped on the first sampling than in the second or third sampling (Table 2). This was due to lower captures of Acarina in the final sampling, and to strongly declining captures of Araneida and Coleoptera (Table 2). Conversely, there were significantly more Diptera captured in the third sampling than the first and second (Table 2).

Table 2. Mean abundance and species richness per log for various arthropod taxa for the three different sampling periods. Data are pooled across the three site types. Numbers in brackets are standard errors. For significant taxa (bold), numbers with the same letter are not significantly different at $\mathrm{p}=0.05$.

\begin{tabular}{|c|c|c|c|c|c|c|c|c|}
\hline \multirow{2}{*}{ Taxon } & \multicolumn{4}{|c|}{ Abundance } & \multicolumn{4}{|c|}{ Richness } \\
\hline & May-Jul & Jul-Aug & Aug-Sep & $\mathrm{p}$ & May-Jul & Jul-Aug & Aug-Sep & $\mathrm{p}$ \\
\hline All arthropods & $33.3(5.0)$ & $28.8(3.7)$ & $33.5(5.8)$ & .743 & $12.5^{\mathrm{a}}(1.0)$ & $9.6^{b}(0.6)$ & $9.5^{b}(0.8)$ & .029 \\
\hline Collembola & $14.8(3.2)$ & $9.3(1.8)$ & $16.4(5.3)$ & .389 & $3.7(0.4)$ & $3.0(0.3)$ & $2.8(0.3)$ & .091 \\
\hline Acarina & $8.8(1.8)$ & $12.7(2.5)$ & $9.1(2.3)$ & .319 & $2.4^{\mathrm{ab}}(0.3)$ & $2.7^{\mathrm{a}}(0.2)$ & $1.9^{b}(0.2)$ & .050 \\
\hline Araneida & $2.2^{\mathrm{a}}(0.5)$ & $0.9^{b}(0.3)$ & $0.3^{\mathrm{b}}(0.1)$ & .001 & $1.5^{\mathrm{a}}(0.3)$ & $0.7^{b}(0.2)$ & $0.3^{b}(0.1)$ & .001 \\
\hline Coleoptera & $2.2(1.3)$ & $0.5(0.2)$ & $0.2(0.1)$ & .157 & $0.9 \mathrm{a}(0.3)$ & $0.3 b(0.1)$ & $0.3 b(0.1)$ & .047 \\
\hline Diptera & $2.3^{\mathrm{a}}(0.4)$ & $3.5^{\mathrm{a}}(0.5)$ & $5.3^{b}(0.8)$ & .000 & $1.5^{\mathrm{a}}(0.2)$ & $1.8^{\mathrm{ab}}(0.3)$ & $2.5^{b}(0.3)$ & .020 \\
\hline
\end{tabular}

\section{Assemblage Composition}

Community differences were clearly apparent between the three treatment age groups in the CAP ordination (Figure 3a), and assemblages among each group were significantly different from each other (permutation test 
$P<0.001$ ). The MDS ordination plot showed a similar pattern (Global $\mathrm{R}=0.41, P=0.001$ ), although sample sites for the 5-year old site type were more widely scattered (Figure 3b). In both CAP and MDS analyses, the 15 year-old rehabilitated areas appeared more similar to the unmined forest than did the 5 year old rehabilitated areas. Results from the ANOSIM analyses indicated that differences between the 15-year-old rehabilitation and unmined forest $(\mathrm{R}=0.535)$ were slightly less than between unmined forest and the younger 5-year-old rehabilitation $(\mathrm{R}=0.37$ ) or between the two ages of rehabilitation $(\mathrm{R}=0.36)$. The ANOSIM test indicated no differences related to $\log$ species $(\mathrm{R}=0.011)$.

Consistent with the univariate results, the groups Araneida, Coleoptera and to a lesser extent Diptera contributed most to the community differences between the three forest site types (Appendix 1). Of the 36 arachnid species collected, 16 were found only from 5-year-old rehabilitation while 6 were restricted to unmined forest sites and a further 8 species to 15-year-old rehabilitation (Appendix 1). Only a single species was collected from all three forest site types. Similarly, of the 22 Coleoptera species collected in the study, a total of 11 species were found only in the 5-year-old rehabilitation and a further 9 species found only in unmined forest sites, with no species common across all three site types (Appendix 1). While 5 Diptera species were found in unmined forest sites only and 9 species from rehabilitated sites only, there were a total of 8 species found across all three site types (Appendix 1).
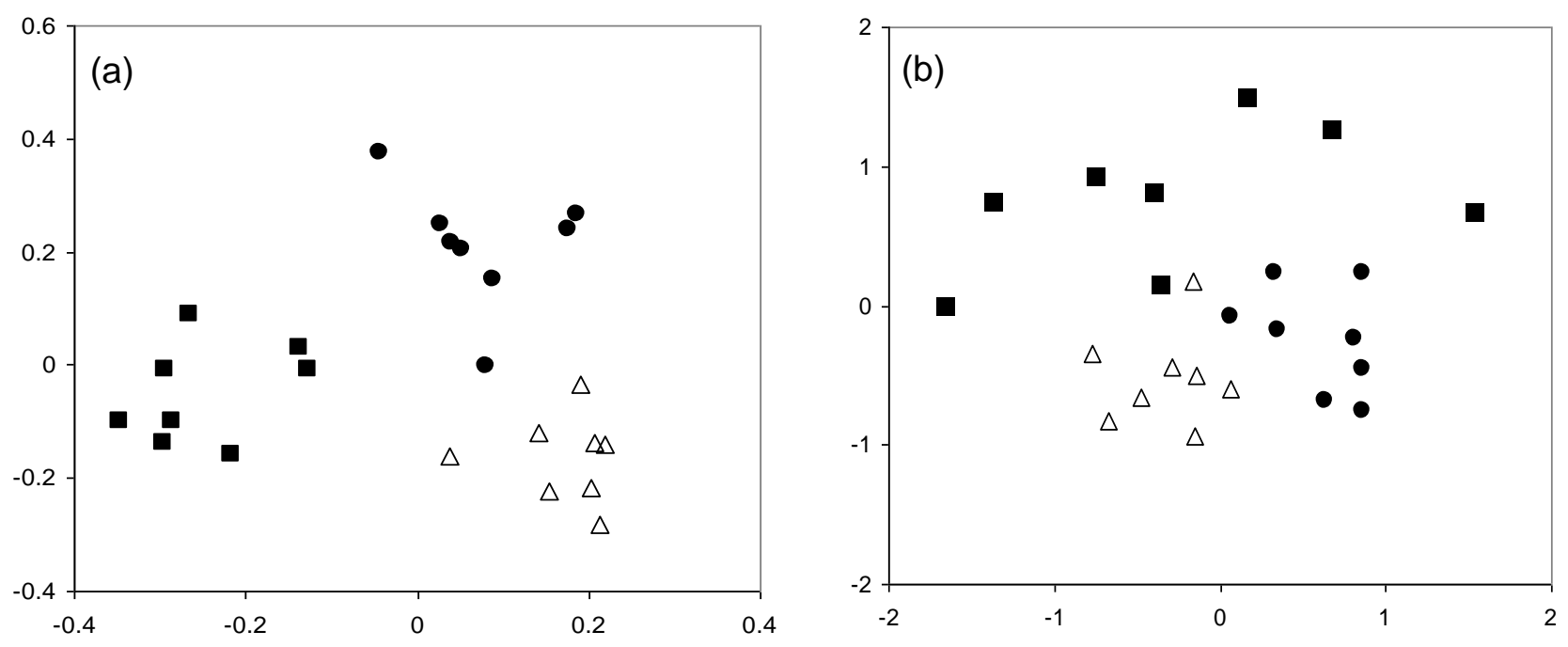

Figure 3. CAP (a) and MDS (b) ordinations of all replicate sites based on community composition $(\boldsymbol{\square}=5$-year old rehabilitation, $\bullet 15$ year old rehabilitation, $\Delta=$ unmined forest). Stress value for $(b)=0.22$.

In the MDS ordination plot (Figure 3b), the vertical axis separated sites with lower litter and tree canopy cover and sites with logs in a less advanced stage of decay at the top of the plot from sites with higher litter and tree cover and logs in a more advanced state of decay towards the bottom of the diagram (Figure 4a,b). Logs in sites towards the top of the ordination plot were also consistently unburnt, while sites lower in the ordination exhibited a greater range from unburnt to mostly burnt (Figure 4c). Understorey cover tended to increase from left to right along the horizontal axis in the MDS ordination, although the association was relatively weaker for 5-year-old rehabilitated sites (Figure 4d). Litter cover alone gave the highest Spearman 
rank correlation in the BIO-ENV procedure $(r=0.413)$, however, none of the environmental variables assessed was able to fully explain differences between the 15 -year-old rehabilitation and unmined forest sites.
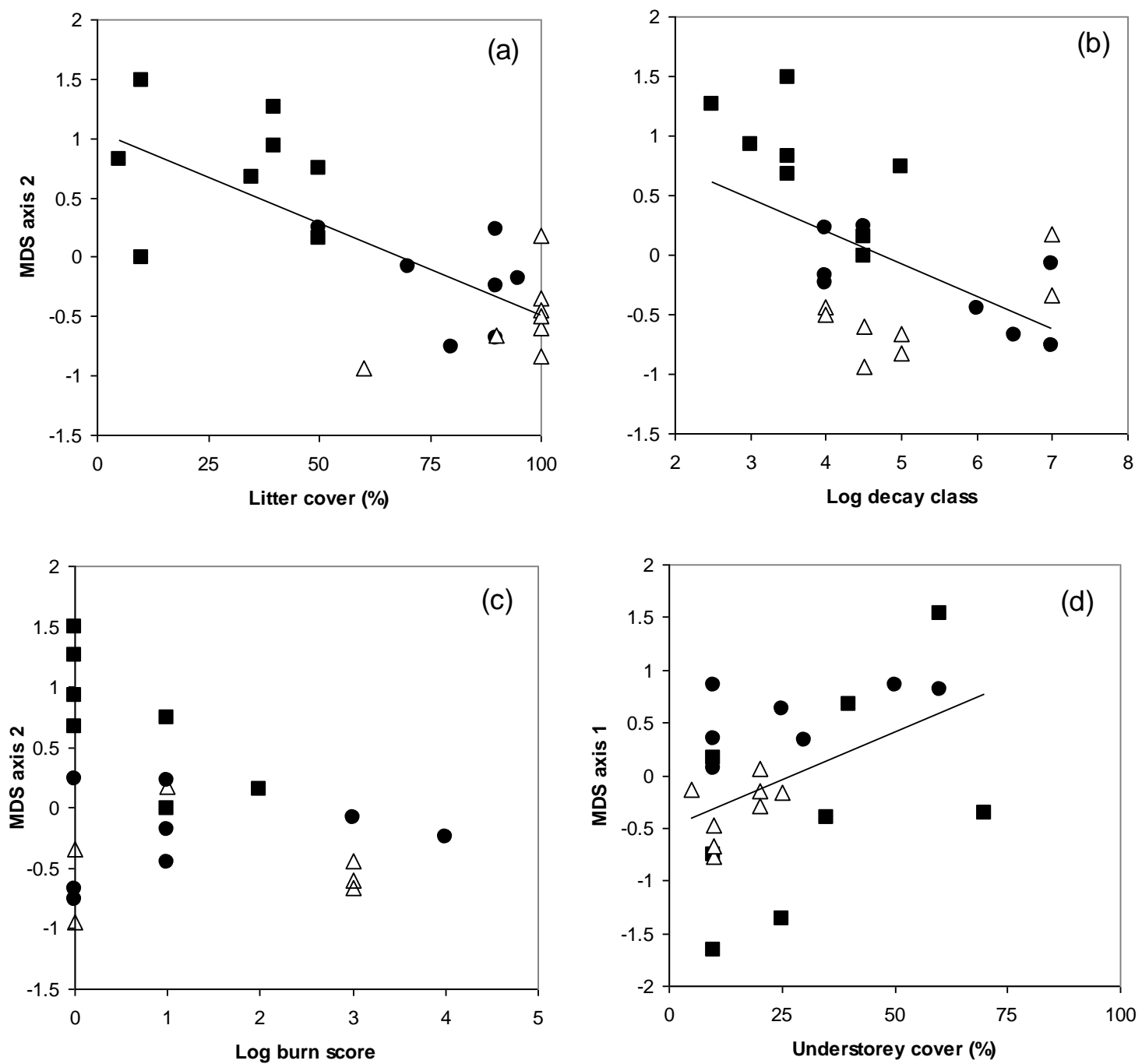

Figure 4. Relationship between MDS ordination scores of community composition and (a) litter cover, (b) log decay class, (c) the proportion of the log's surface area burnt by fire, and (d) cover of understorey plants ( $=$ 5-year old rehabilitation, $\bullet 15$ year old rehabilitation, $\Delta=$ unmined forest). Log decay was scored on a 10point classification from early (1) to advanced (10) stage of decay.

\section{Discussion}

This study has shown that CWD returned to rehabilitated areas contains a rich arthropod fauna. The total specimen count was high (2272) and was evenly distributed over the rehabilitated and unmined forest areas. Arthropod abundance and richness in CWD were statistically similar in 5-year-old rehabilitated areas, 15year-old rehabilitated areas and unmined forest areas. Community composition differed significantly in each forest type, however, there was evidence to suggest that rehabilitated areas became more similar in arthropod community composition to the unmined forest with time. 
The Acarina (mites) are microarthropods which are most commonly associated with decomposition processes (Abbott \& Crossley 1982). The higher abundance of mites in logs in unmined forest sites compared to the 15year-old sites was mostly attributable to two taxa within the Prostigmata, Eupodidae sp. 1 and Prostigmata sp.1. Mites are found at much higher abundances (100's to 1000's) in soil and litter (Majer \& Abbott 1989) when compared to the relatively modest number of specimens found in this study. This difference reflects their preferred habitat of litter and soil rather than logs, but could also relate to their small size which allows them to pass through the mesh and hence yielded lower capture rates in this study. In a previous study in rehabilitated bauxite mines in the jarrah forest, Cuccovia and Kinnear (1999) found a steady increase in litter mite abundance and species richness from two-year-old through to 20 -year-old sites. Unmined forest sites also had higher abundance and richness. However, this was largely due to the dominance and large increases in the Cryptostigmata mites while two of the four groups (Prostigmata and Endostigmata) showed no increase. There was no trend of increasing mite abundance from the 5 to the 15 -year-old sites in the current study, although the unmined forest sites had higher abundances.

Like the mites, the Collembola are small, many species being $1 \mathrm{~mm}$ long or less (Hopkin 1997). Most species would be able to move through the shadecloth mesh used for this study; however, it is still considered that those captured in the tents were associated with the logs or were close to the logs and are relevant to this study. Collembola mostly feed on fungi and plant detritus, and their association with CWD is likely to be with the fungi on the logs and the leaf litter habitat under and around the log. Both litter cover and state of log decay differed strongly between 5-year old rehabilitated forest and the other two forest types (Figure 4), and it is therefore not surprising that litter cover in particular appeared to play a major role in the patterns of community composition observed. Collembola were also the most abundant taxon, exerting a strong influence on the ordination. Four Collembola taxa, Brachystomelidae sp. 1, Entomobryidae sp. 3 and 4 and Sminthuridae sp. 1 were much more abundant in the 15 -year-old and forest sites, but this was balanced by higher abundances of the two Isotomidae, Acanthomurus sp. 1 and Isotomidae sp. 1 in the 5-year-old sites. Collembola populations are highly seasonal (Majer \& Abbott 1989, Driessen \& Greenslade 2004) and this was seen in the dominant taxon in this study, Acanthomurus sp. 1, which was virtually absent in the first sampling period but dominant by the third sampling.

Coleoptera were most abundant in the 5-year old rehabilitated forest sites, which also contained the least decayed $\log$ s with the least amount of burnt surface (Figure $4 \mathrm{~b}, \mathrm{c}$ ). This is consistent with a study by Ulyshen et al. (2004) who found that the total abundance and richness of all wood-borers and bark beetles were highest in recently disturbed areas (cleared) areas. Recently-disturbed areas and their associated woody debris had, on average, roughly twice the species richness and six times the abundance of beetles than the undisturbed forest areas and their associated woody debris. Disturbed areas become less favourable for beetles with time. In the current study, however, there were apparent exceptions to this trend. Two taxa, the carabid beetle Chlaenius sp. 1 and the nitidulid, Thalycrodes sp. 1 were relatively abundant in the 5-year-old sites but absent from the older rehabilitation and the forest sites, but neither of these taxa is a wood borer. Chlaenius is a predatory beetle (as an adult) while Thalycrodes is a fungus feeder (Collett \& Neumann 1995). The anobiid, Deltocryptus sp 1., was the only wood-boring beetle found in the study, but the two Deltocryptus recorded were captured on forest logs. Such exceptions may simply reflect low overall numbers captured in the study 
(22 species, 72 specimens). By comparison, Grove \& Bashford (2003) found 153 species and 1803 individuals in a one year sampling period in a similar number of logs in Tasmanian wet sclerophyll forest.

Because most of the spider specimens captured were juvenile, it is possible that the spider species present utilised the CWD to lay their eggs, taking advantage of the log habitat. This may also reflect the timing of the study, which covered late autumn to spring, rather than summer when more adult spiders would be found. The decline in spider abundance and species richness over the successive sampling periods was presumably caused by removal and non replenishment due to their annual life cycle. In this study, the spiders were mostly ground dwelling (ie. Gnaphosidae, Miturgidae and Lamponidae) as well as some tangled and gum footed web spinners (mostly Theridiidae). Very few orb weavers or other spiders associated with living vegetation were captured other than one philodromid. This is to be expected given the emergence tent method used. The families Gnaphosidae, Lamponidae and Zoridae are hunters which are highly mobile and probably traverse the logs in search of prey and use them as shelter during the day. The Salticidae, Oxyopidae and Selenopsidae (jumping spiders, lynx spiders and flat huntsmen spiders) are ambush predators, which wait to capture passing prey and shelter on the logs. The families Miturgidae and Theridiidae are tangled web spinners and spin their webs in crevices and under the logs. The reason for the higher spider species richness and abundance in the rehabilitated areas is not known. It may be due to more vigorously growing vegetation, leading to more abundant prey. Nichols and Burrows (1985) found that predatory arthropods (mostly spiders) requiring logs and dense leaf litter were less common in young rehabilitated areas than in surrounding unmined forest, whilst those utilising small bushes, open spaces or small amounts of cover were equally or more common in young rehabilitated areas than in the unmined forest. However their study was conducted at a time before CWD was replaced as part of the mine rehabilitation process.

Diptera typically have a rapid life cycle and showed increases in abundance in the final sampling period. This was associated with the seasonality of the study, which commenced in winter and finished in September (spring) which is the moist period of growth and reproduction, particularly of various midges (Cecidomyiidae, Ceratopogonidae), fungus gnats, sciarid and tipulid flies. Sciaridae sp.1 dominated the abundance counts in the Diptera. Although the life history of this species is unknown, the Sciaridae includes many of the commercially important fungus gnats and flies, and they probably live on fungus associated with the CWD.

This study was a preliminary one and found that CWD did house similar arthropod abundances in forest and rehabilitated areas. Nevertheless, differences in assemblage composition of arthropods in forest and rehabilitated areas still persisted 15 years after the rehabilitation had been carried out. Further work is required to investigate which taxa are truly CWD dependent, and if CWD replacement in rehabilitated areas allows return of these species.

\section{Effect of methodology on captures}

There are two issues that need to be considered, firstly the effect of capturing individuals, and hence exhausting the populations inside the tent, and secondly the effect of the mesh size on the ability of various taxa to enter and leave the tent. The decline in arthropod species numbers after the first sampling reflects the enclosure tent method and the life cycle of the animals, as they can be removed and not replaced due to a slow 
life cycle and prevention of re-introduction from outside the tent. This effect was seen in larger species, including members of the Araneida (spiders) and Coleoptera (beetles). Smaller-sized taxa may be able to populate the CWD by entry through the mesh enclosure. Also smaller taxa may have higher intrinsic rates of reproduction and so can replace individuals lost to the trapping. Such taxa, including the Collembola (springtails), did not show a decline over the three capture periods although the Acarina (mites), which are also small in size, showed a decline from the second to third capture period. The ability of individuals to move through the mesh does not affect the aims and outcomes of the study. Small individuals captured in the vials are considered to be associated with the log, regardless of whether they came from outside the tent or were trapped inside the tent. In addition, the same method was used throughout the study, so comparisons between the three different vegetation types are valid. Litter-dwelling arthropods have been shown to be affected by logs even though they are not considered to be CWD dependent. Evans et al (2003) in New Zealand forest, found that in the litter layer threvidae larvae (Diptera) and phlaeothripidae (Thysanura) significantly increased in abundance with increasing distance from logs, while dalodesmidae (Diplopoda), neobisiidae (Arachnida), amphinectidae (Arachnida) and mites in general, significantly decreased in abundance with increasing distance from logs.

The duration of this study was relatively short (121 days); the study may have yielded more specimens if a longer sampling period had been adopted. Arthropods with a longer life cycle, such as some wood boring beetles, may have continued to emerge, especially if the sampling continued into the warmer summer period. However, a longer sampling period will obviously isolate the log for a longer time and will suffer the problem of exhausting the $\log$ of its arthropod inhabitants. A solution to this may be to uncover the $\log$ for periods of time and then recover it for later sampling. The drawbacks would be the extra workload involved and the escape of arthropods that emerge when the log is uncovered. This was beyond the time scale and resources of this current study.

\section{Conclusions}

This study has found that coarse woody debris placed in rehabilitated mines is utilized by a speciose and abundant population of arthropods. Species richness from the groups Araneida, Coleoptera and Diptera was highest in the 5-year old rehabilitated forest, while Collembola and Acarina were better represented in the unmined forest. There was a trend of increasing similarity to the unmined forest in arthropod fauna associated with the development of vegetation and a litter layer in rehabilitated forest sites, and increasing state of log decay. We conclude that over time CWD in rehabilitated areas is capable of supporting arthropod communities similar to those found in unmined forest. Further work is warranted to determine if returning $\log$ s to mined areas facilitates the return of those taxa dependent on CWD.

\section{Acknowledgements}

We would like to thank Brian Heterick (Curtin University), Mark Harvey (WA Museum Collections), Melinda Moir and Shae Callan (Curtin University) for specialist input to identifying various taxa. Terry Rose, and Dianne and Melanie Kasper helped with field work. Simon Grove (Tasmanian Forestry) provided valuable feedback on an earlier draft manuscript. 


\section{References}

Abbott, D.T., Crossley, A.Jr., 1982. Woody litter decomposition following clear-cutting. Ecology 63, 35-42.

Anderson, M.J. and Robinson, J. 2003. Generalised discriminant analysis based on distances. Australian and New Zealand Journal of Statistics 45, 301-8.

Barclay, S., Ash, J.E., Rowell, D.M., 2000. Environmental factors influencing the presence and abundance of a log-dwelling invertebrate, Euperipatoides rowelli (Onychophora: Peripatopsidae). Journal of Zoology 250, 425-436.

Brown, S., Mo, J., McPherson, J.K., Bell, D.T., 1996. Decomposition of woody debris in Western Australian forests. Canadian Journal of Forest Research 26, 954-966.

Clarke, K.R. and Gorley, R.N. (2006) PRIMER v6: User Manual/tutorial. Primer-E Ltd Plymouth.

Collett, N.G., Neumann, F.G., 1995. Effects of two spring prescribed fires on epigeal Coleoptera in dry sclerophyll eucalypt forest in Victoria, Australia. Forest Ecology and Management 76, 69-85.

Cuccovia A., and Kinnear, A. 1999. Acarine (mite) communities colonizing rehabilitated bauxite mine pits in the jarrah forest of Western Australia. Pp. 54-59 in W. Ponder and D. Lunney, editors. The Other $99 \%$ : The Conservation of Biodiversity of Invertebrates, Royal Zoological Society of New South Wales, Mosman, Australia.

Driessen, M.M., Greenslade, P., 2004. Effect of season, location and fire on Collembola communities in buttongrass moorlands, Tasmania. Pedobiologia 48, 631-642.

Evans, A.M., Clinton, P.W., Allen, R.B., Frampton, C.M., 2003. The influence of logs on the spatial distribution of litter-dwelling invertebrates and forest floor processes in New Zealand forests. Forest Ecology and Management 184, 251-262.

Grant, C.D., Koch, J.M., 2007. Decommissioning Western Australia's first bauxite mine: co-evolving vegetation restoration techniques and targets. Ecological Management and Restoration 8, 92-105.

Grove, S.J., Meggs, J.M., 2003. Coarse woody debris, biodiversity and management: a review with particular reference to Tasmanian wet eucalyptus forests. Australian Forestry 66, 258-272. 
Grove, S.J., Bashford, R., 2003. Beetle assemblages from the Warra log decay project: insights from the first year of sampling. Tasforests 14: 117-129.

Harmon, M. E., J. F. Franklin, F. J. Swanson, P. Sollins, S. V. Gregory, J. D. Lattin, N. H. Anderson, S. P. Cline, N. G. Aumen, J. R. Sedell, G. W. Lienkaemper, K. Cromack Jr, and K. W. Cummins. 1986. Ecology of coarse woody debris in temperate ecosystems. Advances in Ecological Research 15:133-302.

Hanula, J.L., 1993. Relationship of wood-feeding insects and coarse woody debris. Workshop on coarse woody debris in southern forests: effects on biodiversity. In; McMinn, J.W., Crossley, D.A., eds. United States Department of Agriculture Forest Service, Athens, Ga., pp. 55-81.

Hingston, F. J., Dimmock, G. M., and Turton, A. G. 1981. Nutrient distribution in a jarrah (Eucalyptus marginata Donn. Ex Sm.) ecosystem in south-west Western Australia. Forest Ecology and Management 3, 183-207.

Hopkin, S.P., 1997. Biology of the Springtails. Insecta:Collembola. Oxford University Press, Oxford, UK.

Horn, S., Hanula, J.L., 2002a. Comparison of arthropod prey of red-cockaded woodpeckers on the boles of long-leaf and loblolly pines. Wildlife Society Bulletin 30, 131-138.

Horn, S., Hanula, J.L., 2002b Life history and habitat association of the broad wood cockroach, Purcoblatta lata (Blattaria: Blattellidae) and other native cockroach in the coastal plain of South Carolina. Annals of the Entomological Society of America 95, 665-671.

Jabin, M., Mohr, D., Kappes, H., Topp, W., 2004. Influence of deadwood on density of soil macro-arthropods in a managed oak-beech forest. Forest Ecology and Management 194, 61-69.

Koch, J.M., 2007. Alcoa's mining and restoration process in south Western Australia. Restoration Ecology Supplement 15, S11-S16.

Kruys, N., Jonsson, B.G., 1999. Fine woody debris is important for species richness on logs in managed boreal spruce forests of northern Sweden. Canadian Journal of Forest Research 29, 1295-1299.

Majer, J.D., Abbott, I., 1989. Invertebrates of the jarrah forest, in Dell, B., (ed.), The Jarrah Forest, Kluwer Academic Publishers, Dordrecht, pp. 111-122

Nichols, O.G., Burrows, R., 1985. Recolonisation of revegetated bauxite mine sites by predatory invertebrates. Forest Ecology and Management 10, 49-64.

Nordén, B., Götmark, F., Tönnberg, M., Ryberg, M., 2004. Dead wood in semi-natural temperate broadleaved woodland: contribution of coarse and fine dead wood, attached dead wood and stumps. Forest Ecology and Management 194, 235-248. 
Siitonen, J., Martikainen, P., Punttila, P., Rauh, J., 2000. Coarse woody debris and stand characteristics in mature managed and old-growth boreal mesic forests in southern Finland. Forest Ecology and Management $128,211-225$.

Stevens, V., 1997. The Ecological Role of Coarse Woody Debris: An Overview of the Ecological Importance of CWD In B.C. Forests, B.C. Ministry of Forests, B.C.

Ulyshen, M.D., Hanula, J.L., Horn, S., Kilgo, J.C., Moorman, C.E., 2004. Spatial and temporal patterns of beetles associated with coarse woody debris in managed bottomland hardwood forests. Forest Ecology and Management 199, 259-272.

Whitford, K.R., Williams, M.R. 2001. Survival of jarrah (Eucalyptus marginata Sm.) and marri (Corymbia calophylla Lindl.) Habitat trees retained after logging. Forest Ecology and Management 146, 181-197.

Whitford, K.R., Guja, L., Phelan, G. 2008. ForestCheck procedure for coarse woody debris assessment. May 2008. Science Division, Department of Environment and Conservation, Perth.

Williams, M.R., Faunt, K., 1997. Factors affecting the abundance of hollows in logs in jarrah forest of southwestern Australia. Forest Ecology and Management 95, 153-160.

Woldendorp, G., Keenan, R.J., 2005. Coarse woody debris in Australian forest ecosystems: a review. Austral Ecology 30, 834-843.

Woldendorp, G., Keenan, R.J., Barry, S., Spencer, R.D., 2004. Analysis of sampling methods for coarse woody debris. Forest Ecology and Management 198, 133-148. 
Appendix 1. Abundance of all arthropod taxa in 5-year-old rehabilitation, 15-year-old rehabilitation and unmined forest (UF) accumulated over the three sampling occasions. Data are ordered alphabetically within groups according to patterns of presence within the three forest site types. Indet. = could not be identified.

\begin{tabular}{|c|c|c|c|c|c|c|c|c|}
\hline Class & Order & Family & Genus & Species & 5 yo & 15 yo & UF & Total \\
\hline Arachnida & Acarina (Mesostigmata) & Indet. & & sp.3 & & & 4 & 4 \\
\hline Arachnida & Acarina (Mesostigmata) & Laelapidae & & sp. 3 & & & 1 & 1 \\
\hline Arachnida & Acarina (Oribatida) & Indet. & & sp.4 & & & 2 & 2 \\
\hline Arachnida & Acarina (Prostigmata) & Anystidae & & sp. 2 & & & 2 & 2 \\
\hline Arachnida & Acarina (Prostigmata) & Anystidae & & sp.1 & & & 1 & 1 \\
\hline Arachnida & Acarina (Prostigmata) & Indet. & & sp. 5 & & & 1 & 1 \\
\hline Arachnida & Araneida & Cyatholipidae & Matilda & sp.1 & & & 1 & 1 \\
\hline Arachnida & Araneida & Donopidae & Gamasomorpha & sp.1 & & & 1 & 1 \\
\hline Arachnida & Araneida & Gnaphosidae & & sp.4 & & & 1 & 1 \\
\hline Arachnida & Araneida & Lamponidae & & sp. 3 & & & 1 & 1 \\
\hline Arachnida & Araneida & Miturgidae & Mituliodon & tarantulinus & & & 1 & 1 \\
\hline Arachnida & Araneida & Theridiidae & & sp.3 & & & 1 & 1 \\
\hline Arachnida & Opiliones & Megalopsalidiae & & sp.1 & & & 1 & 1 \\
\hline Arachnida & Pseudoscopionida & Olpiidae & Beierolpium & sp.1 & & & 1 & 1 \\
\hline Chilopoda & Scolopendromorpha & Cryptopidae & Cryptops & sp.1 & & & 2 & 2 \\
\hline Diplopoda & Polydesmida & Polyxenidae & & sp.1 & & & 1 & 1 \\
\hline Entognatha & Collembola & Sminthuridae & & sp.4 & & & 3 & 3 \\
\hline Entognatha & Diplura & Dipluridae & Chenistonia & tepperi & & & 1 & 1 \\
\hline Insecta & Blattodea & Indet. & & sp.4 & & & 2 & 2 \\
\hline Insecta & Blattodea & Indet. & & sp.9 & & & 2 & 2 \\
\hline Insecta & Blattodea & Indet. & & sp.3 & & & 1 & 1 \\
\hline Insecta & Coleoptera & Anobiidae & Deltocryptus & sp.1 & & & 2 & 2 \\
\hline Insecta & Coleoptera & Anthicidae & Anthicus & sp.1 & & & 1 & 1 \\
\hline Insecta & Coleoptera & Carabidae & Sarticus & sp.1 & & & 1 & 1 \\
\hline Insecta & Coleoptera & Dermestidae & & sp.1 & & & 1 & 1 \\
\hline Insecta & Coleoptera & Staphylinidae & Aleocharine & sp.1 & & & 1 & 1 \\
\hline Insecta & Diptera & Cecidomyiidae & & sp.4 & & & 1 & 1 \\
\hline Insecta & Diptera & Cecidomyiidae & & sp.7 & & & 1 & 1 \\
\hline Insecta & Diptera & Cecidomyiidae & & sp.8 & & & 1 & 1 \\
\hline Insecta & Diptera & Ceratopeperidae & & sp.1 & & & 2 & 2 \\
\hline Insecta & Diptera & Ceratopeperidae & & sp. 2 & & & 2 & 2 \\
\hline Insecta & Diptera & Culieidae & Aedes & sp.1 & & & 1 & 1 \\
\hline Insecta & Diptera & Ptiliidae & Acrotrochis & sp.1 & & & 1 & 1 \\
\hline Insecta & Hemiptera (Sternorrhyncha) & Indet. & & sp.1 & & & 1 & 1 \\
\hline Insecta & Hymenoptera & Ceraphronidae & & sp.1 & & & 1 & 1 \\
\hline Insecta & Hymenoptera & Formicidae & Crematogaster & dispar & & & 1 & 1 \\
\hline Insecta & Hymenoptera & Formicidae & Iridomyrmex & chasei & & & 1 & 1 \\
\hline Insecta & Hymenoptera & Formicidae & Monomorium & sordidum & & & 1 & 1 \\
\hline Insecta & Orthoptera & Gryllidae & & sp.1 & & & 1 & 1 \\
\hline Insecta & Orthoptera & Indet. & & sp.1 & & & 1 & 1 \\
\hline Insecta & Psocoptera & Indet. & & sp.1 & & & 1 & 1 \\
\hline Arachnida & Acarina (Endeostigmata) & Nanorchestidae & & sp.1 & 4 & 7 & 13 & 24 \\
\hline Arachnida & Acarina (Mesostigmata) & Indet. & & sp. 1 & 52 & 27 & 33 & 112 \\
\hline Arachnida & Acarina (Prostigmata) & Eupodidae & & sp.1 & 152 & 35 & 232 & 419 \\
\hline Arachnida & Acarina (Prostigmata) & Indet. & & sp.1 & 29 & 6 & 55 & 90 \\
\hline Arachnida & Acarina (Prostigmata) & Indet. & & sp. 2 & 2 & 5 & 2 & 9 \\
\hline Arachnida & Araneida & Theridiidae & Steatoda & sp.1 & 4 & 14 & 7 & 25 \\
\hline Entognatha & Collembola & Brachystomelidae & & sp.1 & 5 & 39 & 59 & 103 \\
\hline Entognatha & Collembola & Entomobryidae & & sp.3 & 21 & 84 & 100 & 205 \\
\hline Entognatha & Collembola & Entomobryidae & & sp.4 & 3 & 15 & 21 & 39 \\
\hline Entognatha & Collembola & Entomobryidae & & sp. 2 & 4 & 5 & 9 & 18 \\
\hline Entognatha & Collembola & Entomobryidae & & sp.1 & 3 & 2 & 2 & 7 \\
\hline Entognatha & Collembola & Entomobryidae & & sp. 5 & 5 & 7 & 9 & 21 \\
\hline Entognatha & Collembola & Isotomidae & & sp.1 & 102 & 13 & 15 & 130 \\
\hline Entognatha & Collembola & Isotomidae & Acanthomurus & sp.1 & 269 & 55 & 53 & 377 \\
\hline Entognatha & Collembola & Sminthuridae & & sp. 5 & 4 & 7 & 3 & 14 \\
\hline Insecta & Diptera & Sciaridae & & sp.1 & 42 & 73 & 4 & 119 \\
\hline Arachnida & Acarina (Mesostigmata) & Indet. & & sp.2 & & 48 & 2 & 50 \\
\hline Arachnida & Acarina (Oribatida) & Indet. & & sp.2 & 3 & & 3 & 6 \\
\hline Arachnida & Acarina (Prostigmata) & Bdellidae & & sp.1 & 1 & 1 & 1 & 3 \\
\hline Arachnida & Araneida & Orsolobidae & Tasmanoonops & sp. 2 & & 1 & 1 & 2 \\
\hline Chilopoda & Scutigeromorpha & Scutigeridae & Allothereua & maculata & 3 & & 2 & 5 \\
\hline Diplopoda & Polydesmida & Paradoxosomatidae & Antichiropus & variabilis & & 1 & 1 & 2 \\
\hline Diplopoda & Spirostreptida & Lulomorphidae & Atelomastix & sp.1 & & 2 & 3 & 5 \\
\hline
\end{tabular}




\begin{tabular}{|c|c|c|c|c|c|c|c|c|}
\hline Entognatha & Collembola & Entomobryidae & & sp.7 & 2 & 1 & 3 & 6 \\
\hline Entognatha & Collembola & Isotomidae & & sp.2 & & 1 & 2 & 3 \\
\hline Entognatha & Collembola & Sminthuridae & & sp.6 & 1 & & 1 & 2 \\
\hline Entognatha & Collembola & Sminthuridae & & sp.1 & 2 & 1 & 17 & 20 \\
\hline Entognatha & Collembola & Sminthuridae & & sp. 2 & 13 & & 2 & 15 \\
\hline Insecta & Blattodea & Indet. & & sp.1 & 1 & & 3 & 4 \\
\hline Insecta & Diptera & Cecidomyiidae & & sp. 5 & 1 & 1 & 1 & 3 \\
\hline Insecta & Diptera & Cecidomyiidae & & sp.6 & 2 & 7 & 1 & 10 \\
\hline Insecta & Diptera & $\begin{array}{l}\text { Chironomidae } \\
\text { Empididae }\end{array}$ & & sp.1 & 4 & 5 & 1 & 10 \\
\hline Insecta & Diptera & $\begin{array}{l}\text { (Tachydromiinae) } \\
\text { Mycetophilidae }\end{array}$ & & sp.1 & 1 & & 1 & 2 \\
\hline Insecta & Diptera & (Sciophilinae) & & sp.1 & 5 & 6 & 1 & 12 \\
\hline Insecta & Diptera & $\begin{array}{l}\text { Phoridae } \\
\text { Tipulidae }\end{array}$ & & sp.1 & 2 & 5 & 1 & 8 \\
\hline Insecta & Diptera & $\begin{array}{l}\text { (Linioninae) } \\
\text { Tipulidae }\end{array}$ & & sp.1 & 5 & & 5 & 10 \\
\hline Insecta & Diptera & (Tipulinae) & & sp.1 & 1 & 8 & 3 & 12 \\
\hline Insecta & Hymenoptera & Formicidae & Tapinoma & sp. JDM 78 & 5 & 1 & 3 & 9 \\
\hline Insecta & Hymenoptera & Formicidae & Ochetellus & glaber & 11 & 4 & 1 & 16 \\
\hline Insecta & Hymenoptera & Formicidae & Camponotus & michaelseni & & 3 & 1 & 4 \\
\hline Insecta & Hymenoptera & Scelionidae & & sp.1 & 3 & & 2 & 5 \\
\hline Insecta & Hymenoptera & Scelionidae & & sp.2 & & 1 & 2 & 3 \\
\hline Insecta & Orthoptera & Anastostomatidae & Leponosandrus & lepismoides & 1 & & 2 & 3 \\
\hline Insecta & Thysanoptera & Indet. & & sp.1 & 2 & & 2 & 4 \\
\hline Malacostraca & Isopoda & Indet. & & sp.1 & 2 & & 1 & 3 \\
\hline Arachnida & Acarina & Ixodidae & & sp.1 & 1 & 1 & & 2 \\
\hline Arachnida & Araneida & Clubionidae & Clubiona & sp.1 & 2 & 1 & & 3 \\
\hline Arachnida & Araneida & Gnaphosidae & & sp.1 & 2 & 1 & & 3 \\
\hline Arachnida & Araneida & Salticidae & & sp.1 & 2 & 1 & & 3 \\
\hline Arachnida & Araneida & Theridiidae & Theridion & sp.1 & 1 & 3 & & 4 \\
\hline Arachnida & Araneida & Zoridae & & sp.1 & 1 & 2 & & 3 \\
\hline Entognatha & Collembola & Entomobryidae & & sp.6 & 1 & 2 & & 3 \\
\hline Entognatha & Collembola & Sminthuridae & & sp. 3 & 6 & 1 & & 7 \\
\hline Insecta & Coleoptera & Curculionidae & & sp.1 & 4 & 1 & & 5 \\
\hline Insecta & Dermaptera & Anisolabidae & & sp.1 & 9 & 2 & & 11 \\
\hline Insecta & Diptera & Cecidomyiidae & & sp.2 & 1 & 3 & & 4 \\
\hline Insecta & Diptera & Cecidomyiidae & & sp.3 & 6 & 2 & & 8 \\
\hline Insecta & Diptera & Ceratopogonidae & & sp.1 & 5 & 5 & & 10 \\
\hline Insecta & Diptera & Ceratopogonidae & & sp.3 & 1 & 1 & & 2 \\
\hline Insecta & Diptera & Mycetophilidae & & sp.2 & 1 & 4 & & 5 \\
\hline Insecta & Hymenoptera & Formicidae & Camponotus & terebrans & 1 & 12 & & 13 \\
\hline Insecta & Hymenoptera & Formicidae & Iridomyrmex & bicknelli & 1 & 2 & & 3 \\
\hline Insecta & Thysanoptera & Indet. & & sp.3 & 12 & 2 & & 14 \\
\hline Arachnida & Acarina (Oribatida) & Indet. & & sp.1 & 3 & & & 3 \\
\hline Arachnida & Araneida & Enoplognathidae & Enoplognatha & sp.1 & 1 & & & 1 \\
\hline Arachnida & Araneida & Gnaphosidae & & sp.2 & 1 & & & 1 \\
\hline Arachnida & Araneida & Gnaphosidae & & sp. 3 & 1 & & & 1 \\
\hline Arachnida & Araneida & Gnaphosidae & & sp.5 & 1 & & & 1 \\
\hline Arachnida & Araneida & Lamponidae & Lampona & brevipes & 1 & & & 1 \\
\hline Arachnida & Araneida & Lamponidae & & sp.1 & 1 & & & 1 \\
\hline Arachnida & Araneida & Lamponidae & & sp.2 & 2 & & & 2 \\
\hline Arachnida & Araneida & Miturgidae & & sp.1 & 1 & & & 1 \\
\hline Arachnida & Araneida & Miturgidae & & sp.2 & 1 & & & 1 \\
\hline Arachnida & Araneida & Molycridae & Molycria & quadricauda & 2 & & & 2 \\
\hline Arachnida & Araneida & Orsolobidae & Tasmanoonops & sp.1 & 1 & & & 1 \\
\hline Arachnida & Araneida & Oxyopidae & Oxyopes & sp.1 & 1 & & & 1 \\
\hline Arachnida & Araneida & Textricellidae & Textricella & sp.1 & 1 & & & 1 \\
\hline Arachnida & Araneida & Theridiidae & Euryopis & sp.1 & 1 & & & 1 \\
\hline Arachnida & Araneida & Theridiidae & & sp.1 & 1 & & & 1 \\
\hline Arachnida & Araneida & Theridiidae & & sp.2 & 1 & & & 1 \\
\hline Arachnida & Araneida & Trachycosmidae & Trachycosmus & sculptilis & 2 & & & 2 \\
\hline Insecta & Blattodea & Indet. & & sp.2 & 1 & & & 1 \\
\hline Insecta & Blattodea & Indet. & & sp. 5 & 2 & & & 2 \\
\hline Insecta & Coleoptera & Carabidae & Chlaenius & sp.1 & 28 & & & 28 \\
\hline Insecta & Coleoptera & Coccinellidae & Rodolia & sp.1 & 1 & & & 1 \\
\hline Insecta & Coleoptera & Corylophidae & Sericoderus & sp.1 & 7 & & & 7 \\
\hline Insecta & Coleoptera & Elateridae & Agrypnus & sp.1 & 2 & & & 2 \\
\hline Insecta & Coleoptera & Leiodidae & Eublackburniella & sp.1 & 1 & & & 1 \\
\hline Insecta & Coleoptera & Nitidulidae & Thalycrodes & sp.2 & 1 & & & 1 \\
\hline Insecta & Coleoptera & Nitidulidae & Thalycrodes & sp.1 & 11 & & & 11 \\
\hline Insecta & Coleoptera & Pselaphidae & & sp.1 & 1 & & & 1 \\
\hline
\end{tabular}




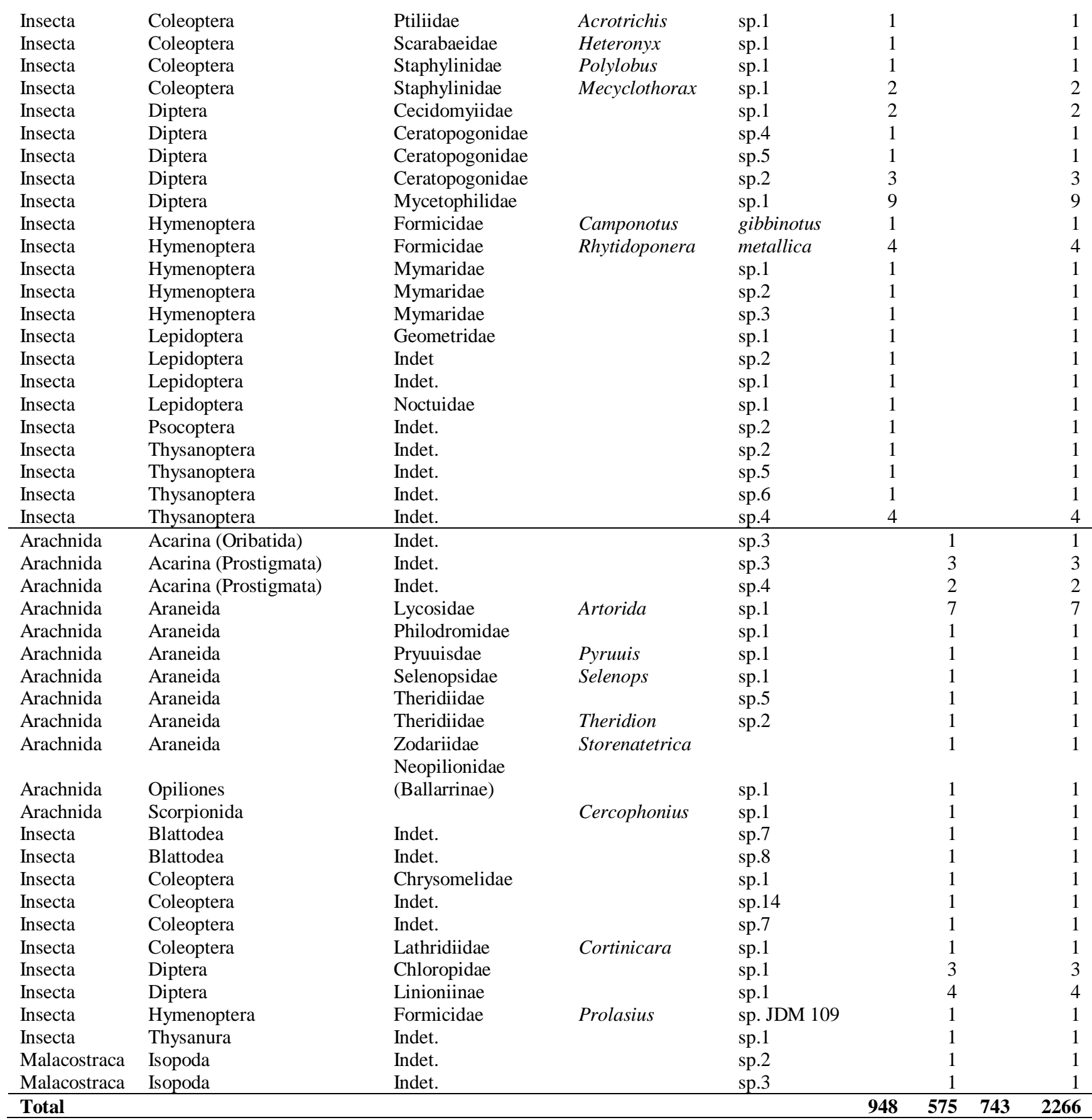

